\title{
ВИКТОРИЯ МАЛКИНА
}

(iD) https://orcid.org/0000-0003-1323-7683

Российский государственный гуманитарный университет

Институт филологии и истории

Кафедра теоретической и исторической поэтики

125993, ГСП-3, Москва

Миусская площадь, д. 6

poetika@gmail.com

\section{«АВТОПОРТРЕТ» И ПРОБЛЕМЫ ВИЗУАЛЬНОГО В РОССИЙСКОЙ ПОЭЗИИ ХХ ВЕКА}

\author{
"SELF-PORTRAIT" AND THE ISSUES OF THE VISUAL \\ IN THE RUSSIAN POETRY OF THE $20^{\text {th }}$ CENTURY
}

The paper analyses visual poetics in a number of poems entitled "Self-portrait". The author construes the visual in literature as a category of poetics which assumes the visibility of the inner world of the poem for the lyrical subject and for the reader. The visual in the lyric poetry can be expressed in various ways, including allusions to the genres of visual arts, for example, to self-portraiture.

The topic undertaken is relevant, given the currently growing interest in intermediality in literature in general and in poetry in particular. What is new about the present research is that poetic self-portraits are considered here from the point of view of visual poetics. The main purpose of the paper is to analyse the ways in which the lyrical subject visually represents his or her own image. The following aspects are touched upon: the interaction of poetry and painting, the common and the differentiating features of a pictorial and a lyrical self-portrait; the use of visual details; the subjective structure of poems and the lyrical plot. There is also an attempt to build a typology of poetic self-portraits, depending on how the lyrical subject sees himself/herself as another. The material of the study includes poems by Aleksandr Kushner, Ilya Selvinsky, Andrei Voznesensky, Osip Mandelshtam, Konstantin Bolshakov, Valentin Katarsin, Nikolai Rylenkov, and others.

Keywords: the visual in poetry, self-portrait, lyrical subject, lyrical plot.

В статье анализируется поэтика визуального в стихотворениях, озаглавленных «Автопортрет». Визуальное при этом понимается как категория поэтики, предполагающая зримость внутреннего мира стихотворения для лирического субъекта и для читателя. Визуальное в лирике может выражаться разными способами, в том числе и аллюзиями на жанры визуальных искусств, например, на автопортрет.

Актуальность статьи заключается в выросшем в последнее время интересе к интермедиальности в литературе вообще и в лирике, в частности. Новизна работы состоит в рассмотрении поэтических автопортретов с точки зрения поэтики визуального. Основная цель статьи - анализ способов визуальной репрезентации лирическим субъектом 
своего собственного образа. Затрагиваются следующие аспекты: взаимодействие лирики и живописи, общие и различные черты между живописным и лирическим автопортретом; использование визуальных деталей; субъектная структура стихотворений и лирический сюжет. Также делается попытка выстроить типологию автопортретов в лирике в зависимости от способов ви́дения лирическим субъектом себя: «Я» как взаимодействие «Я» и другого; «Я» как другой либо «Я» с точки зрения других. Материалом исследования послужили стихотворения А. Кушнера, И. Сельвинского, А. Вознесенского, О. Мандельштама, К. Большакова, В. Катарсина, Н. Рыленкова, и др.

Ключевые слова: визуальное в лирике, автопортрет, лирический субъект, лирический сюжет.

Тема «автопортрет в литературе» достаточно обширная и отнюдь не новая. Однако в большинстве случаев слово «автопортрет» употребляется в метафорическом смысле: подразумевается, что биографический автор воссоздает в художественном тексте свой собственный портрет. И исследования строятся на том, что портрет или фотография реального человека соотносится с вербальным описанием внешности (героя или лирического субъекта) в художественном тексте. Например, С. Н. Колосова определяет лирический автопортрет как

портрет лирического героя произведения, когда грань между автором и лирическим героем чрезвычайно тонка. [...] Высокая степень автобиографичности и внесение в произведение узнаваемых авторских черт внешности позволяет говорить об автопортрете ${ }^{1}$.

Нам кажется, что в таких случаях уместнее говорить об образе автора или лирическом герое и их репрезентации, однако это проблема для отдельного исследования.

Во избежание двусмысленностей мы выбрали стихотворения, в заглавии которых фигурирует слово «автопортрет». Цель статьи - проанализировать специфику визуального в лирических стихотворениях, направленных на воссоздание лирическим субъектом своего собственного образа. Проблема сходства данного образа и реальной личности в наши задачи не входит. Материалом послужила в основном российская поэзия XX в., поскольку в ней такие заглавия достаточно многочисленны и репрезентативны.

Визуальное в лирическом стихотворении мы понимаем как зримость внутреннего мира стихотворения, видимую как для лирического субъекта, так и для читателя. Специфика визуальной картины задается поэтом

${ }^{1}$ С. Н. Колосова, Типология и поэтика портрета в русской лирической поэзии, автореф. дис. на соис. уч. ст. д. ф. н., Москва 2012, с. 25. 
и воспринимается читателем в рамках его собственного зрительского и читательского опыта. Таким образом, визуальное - это свойство поэтики вербального лирического текста.

В репрезентации и рецепции визуального в литературе вообще и в лирике, в частности, могут быть две основные стратегии: прямое и трансгрессивное зрение. Стратегия прямого зрения предполагает либо неподвижность точки зрения наблюдателя, либо ее постепенное движение, дистанцирование и отделение наблюдателя от читателя (зрителя), апелляцию к привычному читателю жизненному и визуальному опыту. То есть прямое зрение создает жизнеподобные образы. Трансгрессивное зрение размывает границы между субъектами либо способствует их нарушению. Такое зрение допускает несколько равноправных точек зрения и втягивает читателя-зрителя во внутренний мир произведения. Соответственно, и образы, которые возникают при трансгрессивном зрении, гротескны, абсурдны или фантастичны. Разумеется, в стихотворении вполне могут сочетаться и обе стратегии.

Важнейшим вопросом при рассмотрении визуального в литератуpe - вне зависимости от использованной автором стратегии зрения - является следующий: кто видит в художественном мире и каким образом? Ведь для читателя зримый мир произведения возникает в зависимости от способа ви́дения субъекта речи, т. е. того, кто видит и изображает мир в данном художественном тексте. Если говорить о лирической поэзии, то в центре оказывается лирический субъект. При репрезентации визуального лирический субъект становится носителем точки зрения в буквальном смысле слова: именно он - тот, кто видит внутренний мир произведения, и от его позиции зависит то, что видит читатель. То есть центральной категорией для анализа визуального в лирике является эксплицитное или имплицитное зрение лирического субъекта, в случае автопортрета - это ви́дение самого себя.

Способы репрезентации визуального могут быть различными (лирический сюжет, образ, композиционно-речевые формы - описания, экфрасис, сон и др.). Одним из таких способов является отображение визуальных искусств, в частности, аллюзии на жанры живописи. Если такая отсылка возникает в заглавии, то это сразу задает стратегию восприятия лирического текста через призму визуального искусства, апеллирует к зрительному воображению читателя.

Таким заглавием, заставляющем «читателя стать зрителем», по выражению В. Набокова, является «Автопортрет». Стихотворения с таким названием есть, например, у Осипа Мандельштама, Ильи Сельвинского, Константина Большакова, Андрея Вознесенского, Николая Рыленкова, Игоря Шевчука, Пабло Неруды, Роберта Крили, Эдварда Хирша, Фрэнка Бидарта, 
Синтии Круз, Натали Эстадо, Аттипата Кришнасвами Рамануджана, Адама Загаевского, и др. Есть и немало вариаций: Мой портрет Александра Пушкина, Автопортрет с бритвой и помазком Александра Кушнера, Автопорmрет в шляпе и Автопортрет без шляпь Валентина Катарсина, Автопортрет на фоне Дмитрия Быкова, Автопортрет в профиль Веры Павловой, Яркосиний автопортрет (Bright Blue Self-Portrait) Фрэнка Лимы, Автопортрет в золотом кимоно (Self-portrait in a Gold Kimono) Генри Коула, Автопорmpeт с наушниками (Self-Portrait with Headphones On) Илианы Роча, и др.

Очевидно, что это заглавие достаточно популярно, хотя в первую очередь автопортрет ассоциируется для нас с живописью. В живописи автопортрет - это «портрет, в котором художник изображает сам себя, обычно используя для этого зеркало. Особенность автопортрета прежде всего в том, что он „говорит” со зрителем от первого лица - о времени и о себе; это монолог художника...»². Жанр этот достаточно исследован, и можно выделить следующие его особенности, которые могут быть применимы к разным формам искусства, не только живописным и не только визуальным.

Автопортрет - это форма саморефлексии, самопознания художника и самосознания культуры. В нем передается отношение художника к миру и самому себе. Это отношение может быть разным - резко критическим, самовосхваляющим, попыткой воспроизвести свой собственный облик или, наоборот, нарисовать некую маску, с акцентом на внешнем или на внутреннем. Но в любом случае, это удвоение самого себя за счет художественного образа, опосредованного вымыслом ${ }^{3}$. При этом «в автопортретном образе постигается сам процесс отражения художником мира и мира в художнике» ${ }^{4}$, это образное изображение диалога художника с самим собой, при этом «стремлению изобразить себя сопутствует зеркальное видение себя как Другого», а «узнавание себя как Другого включает и узнавание себя другим» ${ }^{5}$.

«Введение автопортрета в изобразительное произведение в связи с его зеркальной, удваивающей природой неизменно переформулирует художественный текст, взламывая границы, осуществляя связь изображения со зрителем» ${ }^{6}$, пишет А. В. Ляшко. А А. В. Марков замечает, что «в литературе автопортретность осмысляется и в романах, и в поэзии как

${ }^{2}$ Aвтопортрет, [в:] Искусство: энциклопедия, гл. ред. и авт. проекта проф. А. П. Горкин, Москва: РОСМЭН 2007, с. 9.

${ }^{3}$ См.: С. В. Крузе, Автопортрет как форма самопознания личности художника, автореф. дис. на соис. уч. ст. к. филос. н., Ростов-на-Дону 2004, с. 10-11.

${ }^{4}$ А. В. Ляшко, Автопортрет как феномен самосознания культуры, дис. на соис. уч. ст. к. культурологии, Санкт-Петербург 2001, с. 14.

${ }^{5}$ Там же, с. 183.

${ }^{6}$ Там же, с. 182. 
„репрезентация репрезентации”, способная менять не только установки субъективности, но и ход сюжета» ${ }^{7}$.

То есть автопортрет всегда связан с ви́дением себя как другого. Если говорить о соответствующих стихотворениях, то, с нашей точки зрения, можно выделить три варианта такого ви́дения в лирике:

- «Я» как взаимодействие «Я» и другого;

- «Я» как другой;

- «Я» с точки зрения других.

Для подтверждения данной гипотезы остановимся подробнее на каждой из этих разновидностей, анализируя наиболее репрезентативные тексты. Исходя из нашего понимания феномена визуального в лирике, будем при анализе обращать внимание на следующие аспекты: субъектная организация, движение взгляда субъекта, лирическая ситуация и лирический сюжет, а также визуальные детали.

«Я»как взаимодействие «Я» и другого

К этому типу «автопортретов» относятся стихотворения И. Сельвинского Автопортрет, А. Кушнера Автопортрет с бритвой и помазком, А. Вознесенского Автопортрет и др.

В стихотворениях Сельвинского и Кушнера лирическая ситуация одинакова: человек перед зеркалом. Напомним, что именно зеркало использует художник для создания автопортрета в изобразительном искусстве. В обоих стихотворениях лирический субъект, описывая себя, также смотрится в зеркало.

Стихотворение Сельвинского строится на анафоре «я вижу» (первая и пятая строки). То, что лирический субъект видит именно себя, подчеркивается упоминанием зеркала: «Я вижу в зеркалах суровое лицо» ${ }^{8}$. Сюжет стихотворения - то, как «я» описывает свою внешность, увиденную в отражении. Это не просто последовательное описание сверху вниз или от целого к части. Взгляд лирического субъекта перемещается между наиболее значимыми чертами лица, выступающими в качестве деталей. Сначала упоминается общий план («суровое лицо»), затем описывается то, что находится вокруг глаз - веки и брови (но не сами глаза): «Пролет широких век и сдвинутые брови» (т. 1, с. 30). Затем рот и губы, этому

${ }^{7}$ А. В. Марков, Автопортретность в поэтической книге Одиссеаса Элитиса «Монограмма», «Практики и интерпретации» 2018, т. 3, № 4, с. 56.

${ }^{8}$ И. Л. Сельвинский, Избранные произведения: в 2 т., сост. Ц. Воскресенская, Москва: Художественная литература 1989, т. 1, с. 30. 
посвящены две строки: «У рта надутых мышц жестокое кольцо / И губы цвета черной крови» (т. 1, с. 30).

Пятая строка снова начинается с повтора «я вижу», т. е. лирический субъект окидывает себя взглядом, который вновь поднимается вверх: описывается лоб и потом глаза. При описании глаз единственный раз за все стихотворение синонимический ряд, состоящий из конструкций «прилагательное + существительное», сменяется подчинительной конструкцией. И тут оказывается, что это автопортрет человека творческого - поэта или художника («глаза, знакомые с огнем творящих болей»), причем его творчество имеет те же особенности, что и его внешность. Седьмая строка вновь вводит общий план, который отсылает нас к первой строке. Таким образом, «суровое лицо» в начале и «угрюмые черты» в конце оказываются синонимами, и эта синонимичность подчеркивается повтором слова «суровый» в последней строчке: «И из угрюмых черт мне веет силой гроз, / Суровою жестокостью и волей» (там же).

Автопортрет приводит лирического субъекта к автохарактеристике - описанию главных черт характера, повторяющих черты внешности.

В стихотворении Кушнера мотив зеркала также оказывается связан с вполне традиционным мотивом двойника, увиденного в этом зеркале:

Каждый день пред зеркалом, пену взбивая

На щеке, с многоразовой бритвой Gilette

В острожной руке, что за странность такая, -

Вижу я незнакомца...9

Тут лирический субъект видит и описывает не столько себя (или отражение себя), сколько «незнакомца», при этом подчеркивается остранение, т. е., как мы помним, изображение чего-то обычного и привычного с необычной точки зрения. В данном случае - себя, но в отражении, в зеркале. Кстати, термин «остранение» В. Б. Шкловский произвел от слова «странный», и здесь эта странность появляется буквально: «что за странность такая».

В отличие от стихотворения Сельвинского, у Кушнера нет описания черт лица, упоминаются только внешние детали: пена на щеке и бритва в руке у «я», закапанная майка у его отражения. Составив эти две картинки, мы получаем представление о том, как выглядит сам субъект с учетом

${ }^{9}$ А. С. Кушнер, Автопортрет с бритвой и помазком, «Знамя» 2000, № 7, [электронный pecypc] http://znamlit.ru/publication.php?id=1175 [29.03.2020]. 
«непостоянных» признаков, связанных с процессом бритья (не случайно стихотворение называется не вообще Aвmonopmpem, а именно Aвmonopmpem с бритвой и помазком). Единственная постоянная деталь в облике «незнакомца» - он левша (из чего мы можем сделать вывод, что оригинал - правша).

Так же, как и у Сельвинского, у Кушнера важен мотив зрения: лирический субъект видит незнакомца, а незнакомец «смотрит в упор» на лирического субъекта. Этот обмен взглядами - единственная состоявшаяся коммуникация, так как вербальная оказывается невозможной: отражение «не может начать разговор», а сам лирический субъект - не хочет («не надо», «не услышу», «И о чем? До него ли мне» и т. п.). И оказывается, что эта невозможность и нежелание коммуникации распространяется и на других людей. Несостоявшаяся автокоммуникация приводит к тому, что лирический субъект отказывается от коммуникации вообще, сосредоточиваясь на чисто внешнем и не видя внутреннее, глубину («не так уж, поверь, интересна душа»). Но при этом отказе от разговора он, парадоксальным образом, намечается в возникшем обращении «поверь». То есть субъект все-таки начинает разговор со своим двойником, а значит - возможны и другие разговоры в будущем.

В стихотворении Вознесенского нет ситуации «человек перед зеркалом», но, как и у Кушнера, автопортрет фигурирует как двойник «я», только существующий не в зеркале, а в мире самого субъекта. «Я» увиден (и даже услышан) здесь как другой, и этот увиденный образ пугает «я» («Чур меня! Чур! ( SOS!»). В самом тексте нет ни слова не только о зеркале, но и о зрении, даже глаза не упоминаются, а лишь подразумеваются («щурит прищур»). Детали внешности присутствуют только в первой строчке («Он тощ, словно сучья. Небрит и мордаст»), в дальнейшем статическое описание переходит в динамику, движение и речь. Причем это прямая речь, принадлежащая «другому», который обращается к «я». Именно из этих слов другого мы понимаем, что «я»- поэт. В отличие от стихотворения Кушнера, здесь есть вербальная коммуникация между «я» и «другим», но односторонняя - «другой» обращается к «я», а «я» говорит о нем в третьем лице:

Приветик, - хрипит он, - российской поэзии.

Вам дать пистолетик? А, может быть, лезвие?

Вы - гений? Так будьте ж циничнее к хаосу... ${ }^{10}$

${ }^{10}$ А. Вознесенский, Стихотворения и поэмы: в 2 т., вступит. статья, сост., подгот. текста и примеч. Г. И. Трубникова, Санкт-Петербург: Издательство Пушкинского Дома: Вита Нова 2015, т. 1, с. 235. 
Обратим внимание на то, что во всех трех текстах слово «автопортрет» фигурирует только в заглавии, а значит, относится и к «я», и к «другому» в равной степени. То есть автопортрет является суммой «я» и образа «я», существующих внутри художественного мира стихотворения, что предполагает удвоение образа. Заглавие же удваивает его вторично (получается образ в четвертой степени), потому что мы (как читатели) должны увидеть не только взаимодополнительность «я» и «другого» внутри художественного мира, но и их целостное изображение, обращенное к нам. Иными словами, если попытаться визуализировать эти стихотворения, то на картине будут два субъекта, так или иначе взаимодействующие (или, если вернуться к аналогии с живописью, можно представить картину, на который нарисован не просто автопортрет художника, но художник, который пишет свой автопортрет).

\section{«Я» как другой}

В эту группу можно отнести стихотворения О. Мандельштама, К. Большакова и др. В них нет удваивания внутри художественного мира, и основную визуальную составляющую нам дает заглавие стихотворения. Так, в Aвmonopmpeme Мандельштама ${ }^{11}$ вообще нет личных местоимений, только одно относительное («кому»). Зрение как таковое не упоминается, только один раз глаза, причем невидящие («в закрытьи глаз»). Детали (черты внешности) присутствуют только в первой строфе: голова - сюртук - глаза - руки. Обратим внимание, что все они даны либо с определениями, либо в динамике, либо сочетается и то, и другое, что и подчеркивается четвертой строкой («тайник движенья непочатый»). Вторая строфа - скорее характеристика, чем портрет, в ней нет конкретных визуальных деталей, зато в центре - облик поэта. Здесь уже не соотношение «я» и «другого», увиденного в зеркале, а «я», увиденный как «другой».

Аналогичная ситуация в стихотворении Большакова ${ }^{12}$. Только здесь местоимений нет вообще никаких, и динамики, движения тоже фактически нет: описание статично, и на весь текст только один глагол - «мелькнет», связанный со взглядом. Следует отметить, что всё, связанное со зрением, занимает центральное место в данном автопортрете. Это заметно уже на лексическом уровне: глаза упоминаются шесть раз, и еще два раза - взор.

${ }^{11}$ О. Мандельштам, Сочинения: в 2 т., сост. П. М. Нерлера, подгот. текста и коммент. А. Д. Михайлова, П. М. Нерлера, вступит. статья С. С. Аверинцева, Москва: Художественная литература 1990, т. 1, с. 295-296.

${ }^{12}$ К. Большаков, Автопортрет, [в:] Русская поэзия «серебряного века», 1890-1917: антология, Москва: Наука 1993, с. 590. 
Таким образом, именно зрение и взгляд оказываются главным при описании поэта (это здесь тоже подчеркнуто). Из других визуальных деталей есть только цвет волос, пробор, смокинг и пальто. Обратим внимание еще на один аспект: хотя тут нет зеркала, зеркальность присутствует как структурный принцип организации стихотворного текста: за счет лексических повторов строфы как бы отражают друг друга, но отражение не полное. Это своего рода искаженное вербальное зеркало, в котором влюбленный юноша-поэт видит себя как другого. Как и у Мандельштама, на то, что это образ «я», указывает только заглавие.

\section{«Я» с точки зрения других}

В качестве примера можно привести стихотворения В. Катарсина $A$ вmопортрет без шляпы и Автопортрет в шляпе, Н. Рыленкова Автопортрет и др.

В Автопортрете без шляпы Катарсина местоимения есть, но только третьего лица («он»). «Я» тут увидено со стороны, причем глазами других: девочки, алкаша, нищей, прохожего и т. п. Отсюда очевидная неопределенность («Может быть, с большого гонорара / или, может, с премии шальной...» ${ }^{13}$ ) и оценочность («ненормальный»). Визуальных деталей, благодаря которым мы могли бы представить внешний облик субъекта, в тексте нет (кроме шляпы, которой на самом деле тоже нет). Автопортрет дается не просто в динамике, а в действии и взаимодействии с другими: и людьми, и предметами.

В написанном спустя два года Автопортрете в шляпе ситуация аналогична: лирический субъект описывает себя от третьего лица. Упоминаются и действия, и внешние детали (рост, пальто, шляпа), причем главное, что подчеркивается во всех аспектах - странность и непохожесть на других:

Он падал странно - снизу вверх,

[...]

Он был высок, но с виду мал,

$[\ldots]$

Когда все делали ничто,

он ничего не делал,

носил без рукавов пальто,

пил кофе только белый ${ }^{14}$.

${ }^{13}$ В. Катарсин, Автопортрет без шляпы, 45-я параллель, [электронный ресурс] https://45ll.net/valentin_katarsin/stihi/\#avtoportret_bez_shlyapy [29.03.2020].

${ }^{14}$ Там же. 
«Я» возникает только в последнем катрене, когда лирический субъект объясняет своим имплицитным собеседникам, что речь идет о нем самом. Обратим внимание - мотив зрения, необходимого для того, чтобы увидеть в описанной личности лирического субъекта, появляется именно здесь: «Очки наденьте - это я, / полвека с вами живший». Вспомним, что, согласно исследованиям Цв. Тодорова, очки (как и зеркало) являются общепринятым предметом, необходимым для трансгрессии зрения, символом «непрямого, искаженного, извращенного взгляда» ${ }^{15}$. И далее:

Очки и зеркало становятся образом взгляда, который отныне уже не является простым средством привязки глаза к некой точке в пространстве, теперь это не чисто функциональный, прозрачный и переходный взгляд. Эти предметы - в некотором смысле материализованный, непрозрачный взгляд, квинтэссенция взгляда ${ }^{16}$.

В данном случае трансгрессия зрения нужна для того, чтобы не только «я» смог посмотреть на себя глазами других, но и другие увидели в нем его «я».

В стихотворении Рыленкова для того, чтобы увидеть «я» с точки зрения других, дана прямая речь этих «других», описывающих статичный облик субъекта, т. е. рисующих его портрет:

Сказали 6 знакомые просто
На ваши расспросы в ответ:
«Сутулый, высокого роста,
С лицом без особых примет.

Совсем не похож на поэта,

Что вводит в волшебный чертог...»

Случайно услышав все это,

Не много б добавить я смог ${ }^{17}$.

[...]

«Я» потом добавляет историю своего становления (в динамике), скорее объясняя увиденное «другими», чем добавляя какие-то подробности или детали.

${ }^{15}$ Цв. Тодоров, Введение в фантастическую титературу, пер. с фр. Б. Нарумова, Москва: Дом интеллектуальной книги 1999, с. 101.

${ }^{16}$ Там же, с. 102.

${ }^{17}$ Н. Рыленков, Автопортрет, 45-я параллель, [электронный ресурс] https://45ll.net/ nikolay_rylenkov/stihi/\#avtoportret [29.03.2020]. 
Таким образом, «автопортрет» как заглавие лирического стихотворения через ассоциацию с жанром живописи провоцирует читателя к включению воображения и визуализации лирического субъекта, создающего свой портрет вербальными средствами. Это всегда образная саморефлексия, но в ней можно выделить три основных варианта.

Во-первых, это «Я», увиденное с точки зрения других. Эти другие обычно прямо присутствуют в художественном мире стихотворения; возможны элементы фабулы или диалога с ними.

Во-вторых, «Я», увиденный как другой, как бы со стороны. Здесь обычно присутствует грамматическое третье лицо, т. е. внеличные формы авторского высказывания, согласно классификации С. Н. Бройтмана. Но никаких «других», в отличие от предыдущего варианта, тут нет - это именно «остранение» самого себя.

И, наконец, третий вариант, это «Я» как взаимодействие (или конфликт) частей я, «Я» и другого внутри самого себя. Здесь обычно присутствуют раздвоение субъекта, отражение отражения, диалог с собой, мотивы двойничества и зеркала.

Во всех случаях чрезвычайно важна роль заглавия. Именно оно создает условную «раму» вокруг образа лирического субъекта, рефлексия которого о самом себе становится не просто лирическим сюжетом, но и визуальным образом для читателя.

\section{References}

Avtoportret. In: Iskusstvo: entsiklopediya, ed. A. P. Gorkin. Moskva: ROSMEN, 2007: 9.

Katarsin, Valentin. Vse stikhi Valentina Katarsina, 45-ya parallel. https://45ll.net/valentin_ katarsin/stihi/

Kolosova, Svetlana N. Tipologiya i poetika portreta v russkoi liricheskoi poezii. Avtoreferat dissertatsii na soiskanie uchenoi stepeni doktora filologicheskikh nauk. Moskva, 2012.

Kruze, Svetlana V. Avtoportret kak forma samopoznaniya lichnosti khudozhnika. Avtoreferat dissertatsii na soiskanie uchenoi stepeni kandidata filosofskikh nauk. Rostov-na-Donu, 2004.

Kushner, Aleksandr S. “Avtoportret s britvoi i pomazkom”. Znamia. No. 7 (2000). http://znamlit.ru/ publication.php?id=1175

Liashko, Anna V. Avtoportret kak fenomen samosoznaniya kultury. Dissertatsiya na soiskanie uchenoi stepeni kandidata kulturologii. Sankt-Peterburg, 2001.

Mandelshtam, Osip E. Sochineniya: v 2 t. Vol. 1, ed. P. M. Nerlera. Moskva: Khudozhestvennaya literatura, 1990.

Markov, Aleksandr V. "Avtoportretnost v poeticheskoi knige Odisseasa Elitisa Monogramma”. Praktiki i interpretatsii. Vol. 3, No. 4 (2018): 54-67.

Russkaya poeziya «serebrianogo veka», 1890-1917: antologiya, ed. I. Bagdasarian and others. Moskva: Nauka, 1993.

Rylenkov, Nikolai I. Vse stikhi Nikolaya Rylenkova, 45-ya parallel. https://45ll.net/nikolay_ rylenkov/stihi/ 
Selvinskii, Ilia L. Izbrannye proizvedeniya: v 2 t. Vol. 1. Moskva: Khudozhestvennaya literatura, 1989.

Todorov, Tsvetan. Vvedenie v fantasticheskuyu literaturu, transl. B. Narumov. Moskva: Dom intellektualnoi knigi, 1999.

Voznesenskii, Andrei A. Stikhotvoreniya i poemy: v 2 t. Vol. 1, ed. G. I. Trubnikova. Sankt-Peterburg: Izdatelstvo Pushkinskogo Doma: Vita Nova, 2015.

\begin{tabular}{|l|l|} 
Cc) Creative & $\begin{array}{l}\text { @ by the author, licensee Lodz University - Lodz University Press, Lodz, } \\
\text { Poland. This article is an open access article distributed under the terms and } \\
\text { conditions of the Creative Commons Attribution license CC-BY-NC-ND 4.0 } \\
\text { (https://creativecommons.org/licenses/by-nc-nd/4.0/) }\end{array}$ \\
\hline
\end{tabular}

